\title{
Sobre regimes demográficos restritos: comportamento reprodutivo e cultura familiar entre os ucranianos no meio rural paranaense (1895-1980)
}

\author{
Maria Luiza Andreazza*
}

\begin{abstract}
O estudo acompanha a dinâmica familiar de imigrantes originários da área da atual Ucrânia, chegados ao Brasil em 1895 e estabelecidos em área rural do Paraná, na colônia Antonio Olyntho. Dada a alta fecundidade legítima do grupo, nas coortes estabelecidas para o estudo (1895-1949/1950-1980), procurou-se compreender as razões da manutenção de uma descendência final alta ao longo de todo o período analisado (entre 8 e 9 filhos, na primeira coorte, e entre 7 e 8 , na segunda) e o que isso implicou em termos de organização social, familiar e doméstica. Disso restou considerar que o comportamento reprodutivo é fruto de um complexo sistema de representações, no qual interagem modos de conceber as relações de gênero e as intergeracionais, bem como o papel do casamento e da constituição domiciliar. Se assim for, as práticas concernentes à fecundidade correspondem, sobremaneira, ao exercício social de uma determinada visão de mundo. Em especial nos grupos que vivem em certo isolamento social, as chances de reproduzir modelos ancestrais de reposição geracional são favorecidas. Entre os imigrantes estudados, quase um século no Brasil foi insuficiente para mudar o sistema familiar que veio em sua bagagem: aqui continuaram a produzir prole extensa, mesmo que para isso tenham ativado uma continuada migração dos filhos excedentes.
\end{abstract}

Palavras-chave: Fecundidade. Imigrantes. Sistema familiar. Ucranianos.

\section{Introdução'}

\begin{abstract}
Em termos demográficos, todas as mudanças ocorridas na distribuição espacial da população através do tempo podem ser atribuídas a combinações variáveis de crescimento vegetativo e migrações. [...] Para nossos efeitos, o importante é que a redução generalizada no ritmo de crescimento populacional observada na década de 80 reflete a forte queda da fecundidade. Esta foi iniciada no final da década de 60 , generalizada para todas as regiões e classes sociais na de 70 , e acentuada no seu ritmo durante a década de 80. (MARTINE, 1994, p. 8)
\end{abstract}

Com essas palavras, George Martine resume o processo de transformação de- mográfica da sociedade brasileira nas últimas décadas do século XX, cuja dinâmica foi, em grande parte, tributária à redução da fecundidade. Para o autor, já em meados da década de 90 , persistia "não somente a manutenção da queda [da fecundidade], mas também o fato dela ter se processado a um dos ritmos mais acelerados já vistos entre países de dimensões continentais" (MARTINE, 1994, p. 5).

O declínio da fecundidade no Brasil pode ser acompanhado em estudo de Oliveira, Albuquerque e Lins (2004), que avaliaram e corrigiram parâmetros de projeção demográfica realizada pelo IBGE, valendo-se dos resultados do Censo Demográfico de 2000, das Estatísticas de Registros

\footnotetext{
* Doutora em História do Brasil. Professora/pesquisadora de História da Universidade Federal do Paraná e do CNPQ.

1 Agradeço as observações de Luis Antonio Pinto de Oliveira quando comentou esse texto no XV Encontro Nacional de Estudos Populacionais.
} 
Vitais para 1999, 2000 e 2001 e da Pesquisa Nacional por Amostra de Domicílios 2001. Os resultados destacam a vertiginosa queda do número médio de filhos por mulher, no Brasil, na segunda metade do século $X X$, o que se concretiza na crescente diminuição da taxa de fecundidade total.

Para visualizar tais transformações, no presente trabalho foram considerados esses indicadores e isolados aqueles relativos ao período 1950 a 2000 . Desse recorte, em agrupamentos qüinqüenais, resultou a Tabela 1.

Na Tabela 1 observa-se que, até meados da década de 60, a TFT manteve-se ligeiramente superior a seis filhos por mulher. Entretanto, os resultados do Censo Demográfico de 1970 mostraram redução neste indicador (5,76 filhos por mulher), como reflexo da acentuada diminuição da fecundidade no Sudeste. Por se tratar da parte mais urbanizada do país, as mulheres do Sudeste tiveram acesso precoce aos meios anticoncepcionais existentes para evitar uma gravidez não desejada. Além disso, o parque industrial e a rede de comércio e serviços absorveram um número crescente de mão-de-obra feminina, o que favoreceu a essa região ter sido a primeira a experimentar uma redução significativa no nível da fecundidade: quase 2 filhos de 1960 para 1970. Nas demais, o início da transição da fecundidade de altos para baixos níveis começou nos anos 70 e foi constante nas décadas seguintes, muito em função das transformações na sociedade brasileira, de modo geral, e na própria família, de maneira mais particular. Com isso, a fecundidade, em
1991, já se posicionava em 2,89 filhos por mulher e, em 2000, em 2,39. Finalmente, as Estatísticas Vitais do IBGE para 2004 mostram que, nesse ano, o Sul e o Centro-Oeste passaram a ombrear com o Sudeste, à medida que as três regiões apresentaram as menores taxas de fecundidade e, assim, as maiores reduções nos totais dos nascimentos estimados (OLIVEIRA; ALBUQUERQUE; LINS, 2004, p. 58).

As explicações para essas transformações, em particular a precocidade da Região Sudeste em controlar fortemente a fecundidade, estão pautadas em sua maior exposição aos efeitos da modernização geral da sociedade. É sabido que a redução nos níveis de fecundidade não apenas no Brasil, mas em todos os países que apresentaram tal decréscimo, ocorreu a partir da disseminação de "um mínimo de desenvolvimento e de modernização". Se aceita essa premissa, deve-se concordar que, "para alcançar uma redução significativa e acelerada do crescimento populacional, é preciso haver desenvolvimento", pois "o essencial nessa equação são as perspectivas do desenvolvimento e não o controle populacional" (MARTINE,1993, p. 13).

A relação entre progresso e padrão reprodutivo assume relevo quando se comparam diversas regiões do mundo. Os dados fornecidos pela Organização das Nações Unidades permitem avaliar tal relação, pois agrupam perfis populacionais sob diversos critérios. A Tabela 2 apresenta as taxas de fecundidade para o mundo, no período 1950-2000, segundo a localização geográfica da população e indicadores

TABELA 1

Taxa de fecundidade total

Brasil - 1950-2000

\begin{tabular}{lc}
\hline Períodos & Taxas (1) \\
\hline $1950-1955$ & 6,15 \\
$1955-1960$ & 6,15 \\
$1960-1965$ & 6,15 \\
$1965-1970$ & 5,38 \\
$1970-1975$ & 4,72 \\
$1975-1980$ & 4,31 \\
$1980-1985$ & 3,80 \\
$1985-1990$ & 3,10 \\
$1990-1995$ & 2,60 \\
$1995-2000$ & 2,45 \\
\hline
\end{tabular}

Fonte: Oliveira, Albuquerque e Lins (2004, p. 43).

(1) Número médio de filhos por mulher. 
TABELA 2

Taxa de fecundidade total (1)

Regiões do mundo - 1950-2000

\begin{tabular}{lccccc}
\hline Períodos & Mundo & Europa & $\begin{array}{c}\text { América } \\
\text { Latina e } \\
\text { Caribe }\end{array}$ & $\begin{array}{c}\text { Regióes mais } \\
\text { desenvolvidas }\end{array}$ & $\begin{array}{c}\text { Regiões menos } \\
\text { desenvolvidas (3) }\end{array}$ \\
\hline $1950-1955$ & 5,02 & 2,66 & 5,89 & 2,84 & 6,17 \\
$1955-1960$ & 4,96 & 2,66 & 5,94 & 2,82 & 6,02 \\
$1960-1965$ & 4,97 & 2,58 & 5,97 & 2,69 & 6,03 \\
$1965-1970$ & 4,91 & 2,36 & 5,55 & 2,37 & 6,02 \\
$1970-1975$ & 4,49 & 2,16 & 5,05 & 2,12 & 4,44 \\
$1975-1980$ & 3,92 & 1,97 & 4,50 & 1,91 & 4,15 \\
$1980-1985$ & 3,58 & 1,88 & 3,93 & 1,85 & 3,84 \\
$1985-1990$ & 3,38 & 1,83 & 3,43 & 1,83 & 3,41 \\
$1990-1995$ & 3,04 & 1,57 & 3,03 & 1,69 & 3,10 \\
$1995-2000$ & 2,79 & 1,40 & 2,75 & 1,55 & \\
\hline
\end{tabular}

Fonte: Population Division of the Department of Economic and Social Affairs of the United Nations Secretariat, World Population Prospects: the 2004 Revision and World Urbanization Prospects: the 2003 Revision. Disponível em: <http://esa.un.org/unpp>, 09 March 2006

(1) Número médio de filhos por mulher.

(2) Conforme critérios das Nações Unidas, as "regiões mais desenvolvidas" compreendem todas as regiões da Europa, mais América do Norte, Austrália, Nova Zelândia e Japão.

(3) As "regiões menos desenvolvidas" incluem toda a África, a Ásia (excluído o Japão), a América Latina e Caribe, Melanésia, Micronésia e Polinésia. A retirada dos dados optou pelas variações médias.

socioeconômicos, pelos quais a Divisão de População da ONU define as regiões mais ou menos desenvolvidas no planeta.

Se comparadas as taxas apresentadas nas Tabelas 1 e 2, verifica-se que o gradativo declínio no Brasil seguiu a tendência internacional rumo ao ZGP (zero population growth), considerado ideal a ser atingido no período 1960-1970 (CARVALHO, 2001, p.7). Focalizando apenas a Tabela 2, o comportamento fecundo das brasileiras está incluído em duas colunas. Por uma delas, América Latina e Caribe, pode-se constatar que, até os anos 70 , a fecundidade no Brasil seria das mais altas, pois as taxas brasileiras estão acima da média da região. Depois dessa década há um descenso acelerado, levando o Brasil a exibir, no final do período observado, uma taxa de 2,45 filhos por mulher, levemente abaixo dos 2,75 registrados para América Latina e Caribe. Já no que tange a sua presença entre os Países com menor desenvolvimento, os indicadores brasileiros reiteram claramente que a mudança no comportamento reprodutivo se deu nas décadas de 60 e 70, tornando evidente a mudança estrutural no comportamento reprodutivo médio do país.

Todos esses elementos evidenciam que a dinâmica populacional é um instigante campo de observação. $\mathrm{E}$ deles derivam o objetivo desse estudo, que é contrapor os indicadores das macroanálises produzi- das pelo IBGE e pela ONU com aqueles elaborados em perspectiva microanalítica, derivados do acompanhamento do comportamento demográfico de um grupo de imigrantes instalado no sul do Paraná, em 1895, na Colônia Antonio Olyntho (ANDREAZZA, 1999). Trata-se de um estudo histórico, que incluiu entrevistas com moradores da comunidade, realizadas na década de 90, e coleta de dados dos ciclos vital e matrimonial nas atas paroquiais, para o período entre 1895 e 1980. Os dados foram processados pelo Système de Gestion et d'Analyse de Population, software para análise de população, conforme a metodologia Henry/Fleury. As informações referem-se a 8.867 indivíduos (4.443 homens e 4.424 mulheres), ao longo de 85 anos, separados em duas coortes: 1895-1949 e 1950-1980. A discrepância cronológica entre elas deveuse à busca de simetria entre as uniões MF: a coorte 1 possui 281 uniões MF de um total de 1.301 casamentos; e a coorte 2 tem 244 uniões MF de um total de 733 matrimônios. Vale lembrar que, na metodologia Henry/ Fleury, as uniões MF são aquelas em que se têm as datas do nascimento da mãe, do casamento e do fim da união, marcado pela morte de um dos cônjuges.

É importante esclarecer que não se pretende contestar os indicadores produzidos por instituições que detêm alta competência na área demográfica. Sabe-se, porém, que 
uma parcela dos estudiosos mantém cautelosa euforia com o declínio da fecundidade, por entenderem que existem médias que dissimulam contrastes profundos dispersos pelos variados rincões do Brasil, podendo haver pronunciadas variações no padrão reprodutivo quando as investigações analisam segmentos específicos.

Nessa linha, esse estudo serve para destacar uma variação "no comportamento fecundo brasileiro", ao analisar as especificidade verificadas numa comunidade imigrante - em um bolsão populacional isolado, como tantos outros dispersos pelo Brasil. O que se pretende realçar é que as decisões reprodutivas são suscetíveis a diferentes e variadas coerções que partem da ordem biológica e alçam a cultural. De fato, na coexistência de uma multiplicidade de atitudes sociais em face da constituição de prole, estão imbricadas no mínimo escolhas íntimas das mulheres, estratégias adotadas pelos casais, normas religiosas e culturais e a eficácia de políticas públicas concernentes à educação e programas de saúde.

Dado o exposto, manter a discussão que se segue significa assumir que a fecundidade é precioso indicador para avaliar concepções sociais quanto à reposição geracional. Mais diretamente, entende-se que o perfil reprodutivo de um grupo detém ampla imbricação com o sistema familiar praticado que, por sua vez, tem a ver com o conjunto (variável) de funções desempenhadas pela família numa determinada região ou grupo social. Nessa linha, o comportamento fecundo se desenvolve em enquadramentos sociais específicos - no âmbito de certo sistema familiar - "que detém importância capital para a determinação da dinâmica demográfica" (ROWLAND, 1997, p. 14). Tendo isso em vista, torna-se proibitivo supor trajetórias lineares e homogêneas para as transformações demográficas e impõe-se reconhecer que nas diversas temporalidades históricas, incluindo-se as atuais, coexistem diversas organizações sociais da reprodução. Particularmente entre as populações rurais, há um poderoso fator de inércia a impulsionar a reprodução temporal de um sistema familiar (e nele, é obvio, inclui-se o padrão reprodutivo).

\section{Os imigrantes e os estímulos para sua vinda ao Brasil}

Como já mencionado anteriormente, o grupo focalizado nesse estudo é o dos ucranianos emigrados em 1895 e instalados na colônia rural de Antonio Olyntho (PR), que formavam um contingente pequeno, de pouco mais de 2.000 pessoas, originárias da região da Galícia que hoje corresponde à Ucrânia.

No leste europeu, as relações feudais foram legalmente abolidas apenas na esteira das revoluções de 1848. Mesmo assim, em função das dificuldades que o campesinato experimentava desde que foi liberado da condição servil, no final da década de 1800 a servidão era uma memória poderosa.

De maneira geral, os nobres, proprietários de mais de $40 \%$ das terras da região, continuaram a exigir pagamento em trabalho ou em dinheiro para que os camponeses utilizassem as terras até então comunitárias. E eles não eram poucos, pois um censo já em 1902 mostrou que mais da metade das famílias camponesas da Galícia radicava-se em latifúndios da nobreza (HIMKA,1988, p. 146-147). Todavia, suas respostas às exigências senhoriais foi o uso ilegal das terras rústicas e dos pastos. Para se avaliarem as dimensões do conflito, entre 1850 e 1900, apelações sobre os direitos "servis" apareceram em 984 aldeias galicianas: destas, $90 \%$ localizavam-se na Galícia Oriental (HIMKA, 1988, p. 46-49).

De fato, alguns estudos destacam que a forma tradicional das relações de trabalho na Galícia era marcada pelas opressivas cobranças das obrigações servis, o que não gerava incentivos ao trabalho: tudo o que podia mover o camponês para o serviço era a coerção. Porém, sublinha-se que eles opunham resistência à servidão por diversas formas: enviando para as autoridades do Império relatos dos abusos cometidos pelos senhores das terras e pelos oficiais do exército; trabalhando na medida suficiente para escapar do chicote; usando mais tempo que o necessário para a execução das tarefas; ou ainda escolhendo os piores animais e ferramentas em dias de corvéia. Além da violência, outro componente básico que 
mantinha o sistema servil era a concepção, pelas elites locais, de que os camponeses eram todos "brutos". Tal representação era associada a outra: a de um campesinato analfabeto e preso a uma visão de mundo tradicional.

Todavia, mesmo nessas condições, é inegável que a criação do campesinato livre fez emergir duas orientações nas relações de trabalho daquela sociedade: uma herdeira do passado e outra aberta à modernização que vinha do Ocidente. A partir de 1870, ocorreu o incremento da economia de mercado, implementada, porém, muito lentamente. Prova disso foi a parca urbanização, dado que, já em finais da década de 1890 , menos de $16 \%$ da população morava em cidades.

Nessas condições, nas últimas décadas do século XIX, a Galícia era um mundo em transição. A gradativa modernização das relações de trabalho, a expansão da economia capitalista e a ação dos movimentos nacionalistas e populistas que visavam promover o campesinato não tiveram, até o final da década de 1890, tempo suficiente para derrubar o peculiar tradicionalismo de seus comportamentos sociais.

De forma geral, os estudos da organização familiar naquela região apontam que sua lógica não abrigava a individualização. O campesinato ucraniano preservou, efetivamente, grande parte de sua cultura, fundada na convivência comunitária e familiar, até o início do século XX. Os fundamentos dessa cultura garantiam a reprodução social nos moldes tradicionais e era passada de geração em geração na forma de provérbios, canções e histórias que reiteravam a legitimidade de se reproduzirem práticas ancestrais (HIMKA, 1988, p. 196). De fato, os galicianos viviam segundo formas ancestrais e, por isso mesmo, em meados da década de 1890, quando emigraram para o Brasil, trouxeram uma visão de mundo essencialmente camponesa e tradicional.

\section{A criação de um grupo culturalmente homogêneo}

$O$ assentamento em pequenas propriedades rurais foi o modelo vigente para estabelecer imigrantes nos Estados do Sul do Brasil. Cada família recebia um lote de aproximadamente dez alqueires, dispersos pela mata nativa, já que as terras abertas eram mantidas para os latifundiários pecuaristas. Esses lotes dispersavam-se em caminhos vicinais, cuja função era favorecer o trânsito regional e ligar as diversas áreas da colônia à sede, que compreendia um pequeno povoado concentrando a administração colonial, a igreja, a escola, algum comércio e, gradativamente, os demais serviços públicos. Juntamente com os ucranianos, foram encaminhados para Antonio Olyntho imigrantes poloneses e poucos italianos, além de pessoas que migraram dentro do país. Porém, a adesão dos ucranianos ao catolicismo uniata os distanciou dos demais grupos que seguiam o catolicismo romano, o que serviu, desde os primórdios da colônia, para demarcar severa fronteira etno-cultural. Suas especificidades religiosas e o fato de Antonio Olyntho ter sido uma colônia rural com relativo isolamento na sociedade paranaense, no mínimo até 1970 , quando começou a interiorização da rede rodoviária, facilitaram sua concentração espacial, bem como a freqüência a uma única paróquia: Nossa Senhora da Conceição.

Esses fatores forneceram condições ideais para empreender uma reconstituição das famílias, neste estudo. Juntamente com entrevistas e documentação variada, foi possível recompor a lógica do sistema familiar dos imigrantes e de seus descendentes ao longo de um século. A hipótese foi de que a emigração favoreceria a reformulação da rede de significados do grupo, impondo transformações na formação familiar. Com isso, o objetivo fixou-se na tentativa de captar a medida e o ritmo dessas mudanças. A premissa que sustentou esse objetivo foi a de que o exercício de um sistema familiar conforma expressão concreta de uma cultura. Daí, apreender sua morfologia e mapear as transformações ocorridas durante 100 anos equivale a recompor a transformação de uma visão de mundo. Se, nos campos da Galícia, eles criaram um sistema familiar, tornou-se questão investigativa perceber até quando esse sistema pautado em uma experiência camponesa teve eficácia; quando 
e se ele encontrou dificuldades para seu exercício na terra de adoção; e como se apresentava esse sistema 100 anos após a imigração.

\section{Casar e procriar}

$\mathrm{Na}$ trajetória de vida das moças e rapazes ucranianos e seus descendentes estabelecidos na colônia Antonio Olyntho, o casamento era uma das alternativas mais prováveis. Os filhos dos pioneiros perceberam, inclusive, o valor da família enquanto unidade para o trabalho, já que viveram com seus pais o desenraizamento geográfico e as dificuldades para organizar uma nova vida. Nesse aspecto, o depoimento de um homem com memória dos primeiros tempos enfatiza que as pessoas "sem família não tinham condições de se instalarem na colônia". Portanto, a ajuda de um núcleo familiar conformava condição necessária para vencer as dificuldades iniciais para o estabelecimento dos imigrantes. De fato, a partir do acompanhamento das trajetórias de vida de rapazes presentes nas listagens dos emigrantes e com idade para casar, verificou-se que aqueles radicados na casa de seus pais demoraram de três a cinco anos para se casarem, enquanto os que se tornaram proprietários de lotes morando sozinhos casaram-se num prazo menor, ou migraram da colônia.

Esses jovens, quando comparados com o padrão europeu ocidental de casamento, uniam-se relativamente cedo (HAJNAL, 1965). Entre 1895 e 1949, conforme a Tabela 3, as moças casavam-se, em média, aos 21 e os rapazes, aos 25,4 anos. Tal padrão de idade só modificou-se a partir da terceira geração nascida no Brasil: elevou-se para 24,2 anos entre as moças e para 27,5 anos entre os rapazes, após 1950 (Tabela 4). O cálculo das idades médias de ambas as tabelas considerou apenas o casamento entre celibatários. No entanto, quando se incluem também recasamentos não há uma alteração substantiva nas idades médias dos cônjuges: 21,3 anos para as mulheres e 25,9 anos para os homens, na primeira coorte, e 24,5 e 27,9 anos, respectivamente, na segunda coorte.

Assim, na primeira coorte, as moças casavam-se, preferencialmente, entre 15 e 24 anos (52\%); na segunda, essa concentração dilatou-se por mais quatro anos. De qualquer maneira, as noivas entre 15 e 19 anos, que na primeira coorte representavam $29,1 \%$, ainda constituíam uma parcela considerável na segunda (26\%), ou seja, a partir de 1950. Como novidades na segunda coorte, têm-se o maior número de noivas entre 20 e 24 anos e a ocorrência de primeiro casamento em todas as faixas etárias, inclusive $3 \%$ deles envolvendo muIheres acima de 45 anos. Já entre os rapazes da primeira coorte, a concentração dos casamentos ocorria dos 20 aos 29 anos, passando para a faixa de 20 a 34 anos, na segunda coorte. Dessa maneira, até 1950,

TABELA 3

Casamentos dos imigrantes ucranianos, segundo idade média dos noivos - coorte 1 Município de Antonio Oyntho - 1895-1949

\begin{tabular}{|c|c|c|c|c|c|c|c|c|c|c|c|}
\hline \multirow[b]{2}{*}{ Mulheres } & \multicolumn{11}{|c|}{ Homens } \\
\hline & $\begin{array}{l}10-14 \\
\text { anos }\end{array}$ & $\begin{array}{l}15-19 \\
\text { anos }\end{array}$ & $\begin{array}{c}20-24 \\
\text { anos }\end{array}$ & $\begin{array}{c}25-29 \\
\text { anos }\end{array}$ & $\begin{array}{c}30-34 \\
\text { anos }\end{array}$ & $\begin{array}{c}35-39 \\
\text { anos }\end{array}$ & $\begin{array}{c}40-44 \\
\text { anos }\end{array}$ & $\begin{array}{r}45-49 \\
\text { anos }\end{array}$ & $\begin{array}{c}50 \text { anos } \\
\text { e mais }\end{array}$ & $\begin{array}{l}\text { Indeter- } \\
\text { minada }\end{array}$ & Total \\
\hline $10-14$ anos & - & - & - & 1 & - & - & - & - & - & 1 & 2 \\
\hline $15-19$ anos & . & 6 & 60 & 44 & 4 & - & - & - & - & 60 & 174 \\
\hline 20-24 anos & - & 5 & 50 & 41 & 10 & 2 & - & - & - & 27 & 135 \\
\hline $25-29$ anos & - & 1 & 6 & 17 & 7 & 2 & - & - & - & 8 & 41 \\
\hline 30-34 anos & - & - & 1 & 2 & 3 & 1 & 1 & - & - & 3 & 11 \\
\hline $35-39$ anos & - & - & - & - & - & - & - & - & - & - & - \\
\hline $40-44$ anos & - & - & - & - & - & - & - & - & - & - & - \\
\hline $45-49$ anos & - & - & - & - & - & - & - & - & - & - & - \\
\hline 50 anos e mais & & - & - & - & - & - & - & - & - & - & - \\
\hline Indeterminada & & 6 & 33 & 26 & 3 & 1 & - & - & - & 165 & 234 \\
\hline Total & - & 18 & 150 & 131 & 27 & 6 & 1 & - & - & 264 & 597 \\
\hline
\end{tabular}

Fonte: Andreazza (1999).

Nota: Média de idade ao casar: 25,4 anos para homens e 21,0 anos para mulheres. Desvio-padrão: 3,8 para homens e 3,7 para mulheres. 
TABELA 4

Casamentos dos imigrantes ucranianos, segundo idade média dos noivos - coorte 2 Município de Antonio Oyntho - 1950-1990

\begin{tabular}{|c|c|c|c|c|c|c|c|c|c|c|c|}
\hline \multirow[b]{2}{*}{ Mulheres } & \multirow[b]{2}{*}{$\begin{array}{l}10-14 \\
\text { anos }\end{array}$} & \multicolumn{9}{|c|}{ Homens } & \multirow[b]{2}{*}{ Total } \\
\hline & & $\begin{array}{l}15-19 \\
\text { anos }\end{array}$ & $\begin{array}{l}20-24 \\
\text { anos }\end{array}$ & $\begin{array}{c}25-29 \\
\text { anos }\end{array}$ & $\begin{array}{c}30-34 \\
\text { anos }\end{array}$ & $\begin{array}{c}35-39 \\
\text { anos }\end{array}$ & $\begin{array}{c}40-44 \\
\text { anos }\end{array}$ & $\begin{array}{c}45-49 \\
\text { anos }\end{array}$ & $\begin{array}{c}50 \text { anos } \\
\text { e mais }\end{array}$ & $\begin{array}{l}\text { Indeter } \\
\text { minada }\end{array}$ & \\
\hline $10-14$ anos & - & - & - & - & - & - & - & - & - & - & - \\
\hline 15-19 anos & - & 3 & 47 & 19 & 13 & 1 & 1 & 1 & - & 9 & 94 \\
\hline 20-24 anos & - & 2 & 49 & 44 & 6 & 2 & - & - & - & 11 & 114 \\
\hline 25-29 anos & - & 1 & 15 & 14 & 10 & 1 & - & - & - & 6 & 47 \\
\hline 30-34 anos & - & 1 & 3 & 5 & 4 & 2 & - & - & 1 & 2 & 18 \\
\hline 35-39 anos & - & - & - & 1 & 2 & 3 & - & 1 & 1 & 1 & 9 \\
\hline $40-44$ anos & - & - & - & - & - & - & 1 & - & - & 2 & 3 \\
\hline 45-49 anos & - & - & - & - & - & - & 1 & 1 & 1 & 2 & 5 \\
\hline 50 anos e mais & - & - & - & - & - & - & - & 1 & 4 & 1 & 6 \\
\hline Indeterminada & - & 4 & 23 & 14 & 7 & 1 & - & 2 & 2 & 11 & 64 \\
\hline Total & - & 11 & 137 & 97 & 42 & 10 & 3 & 6 & 9 & 45 & 361 \\
\hline
\end{tabular}

Fonte: Andreazza (1999).

Nota: Idade média ao casar: 27,5 anos para homens e 24,2 anos para mulheres. Desvio-padrão: 7,6 para homens e 7,7 para mulheres.

$89,7 \%$ dos rapazes já estavam casados ao completarem 30 anos; na segunda, com a elevação da idade média ao casar, esse número decresceu para $77,5 \%$. Pode-se observar também que, na primeira coorte, $8 \%$ dos rapazes casavam-se entre 30 e 34 anos; na segunda, esse percentual já era de $13,2 \%$.

Por isso, na primeira coorte, os casais mais freqüentes, em seu primeiro casamento, eram aqueles formados por uma noiva de 15 a 19 anos e um rapaz entre 20 e 24 anos. Essa freqüência simplesmente reitera a manutenção do hábito da constituição de casais em idades precoces. A partir de 1950, esse quadro tem uma pequena modificação com uma maior dispersão à direita, apesar de o casal mais freqüente ainda ser aquele em que ambos os noivos estavam na faixa de 20-24 anos. ${ }^{2}$

Sabendo-se da origem sociocultural dos imigrantes fixados em Antonio Olyntho, a constatação de idades mais ou menos precoces na primeira coorte indicaria que eles mantiveram o padrão de nupcialidade camponês oriental, conforme sugerido por Hajnal tomando como indicadores as idades do casamento e a freqüência do celibato definitivo (HAJNAL, 1965, p. 101-140). A esse respeito, Bideau (1984, p. 50-51) indicou:

nenhuma outra população não européia apresenta modelo de casamento comparável [ao europeu ocidental]. Todavia este modelo não pode ser generalizado para toda a Europa; de fato, ele só cobre os países da cristandade latina. A Europa oriental conheceu modelo diferente. Por exemplo, por volta de 1900, dois terços das mulheres da Europa Ocidental são ainda solteiras, aos 20-24 anos, enquanto na Europa Oriental três quartos delas já estão casadas nesta idade. Aos 45-49 anos o celibato definitivo é cinco vezes mais elevado entre as mulheres européias do Ocidente.

Como se sabe, as populações rurais eram, e muitas delas continuam sendo, organizadas de maneira a exercer fortes pressões em seus componentes para se reproduzirem (BOSERUP, 1987). No caso das gerações de imigrantes analisados, os estudos que focalizam a formação familiar na região de onde emigraram indicam a prática do "casamento oriental" até o início do século XX. Nessa linha, os que se fixaram em Antonio Olyntho mantiveram-se, mesmo

\footnotetext{
2 Explicar essa alteração na idade ao casar na segunda coorte e nas condições daquela comunidade é tarefa espinhosa. De um lado, os homens alegam casar mais tarde, pois saíam temporariamente da localidade para tentar a vida na capital ou em outras frentes pioneiras que o Paraná abriu após os anos 30 e 40 . Particularmente as moças da segunda coorte mencionam haver trabalhado em serviços domésticos nas cidades vizinhas ou mesmo em Curitiba. Outros informaram que a espera para o casamento devia-se à necessidade de esperar que uma parcela dos irmãos emigrasse para poder casar. Dado que essa explicação articula-se mais diretamente ao sistema familiar praticado, essa questão será abordada mais adiante.
} 
sob as novas condições no Brasil, produzindo famílias numerosas, expressas nas altas taxas de fecundidade "legítima" (e não a geral) do grupo em ambas as coortes.

As Tabelas 5 e 6 destacam que as imigrantes, entre 1895 e 1949, casavam-se em torno dos 20 anos e, ao longo de seus ciclos familiares, davam à luz de 8 a 9 filhos. Já a partir de 1950, passaram a se casar mais velhas, por volta de 24 anos, e diminuíram para sete o número de sua prole. Esses números atingem valores maiores quando se observa a taxa de fecundidade por intervalo de idade ao casar: por exemplo, as moças que se casaram dos 15 aos 19 anos apresentaram descendência completa de dez filhos em ambas as coortes, quando a taxa bruta brasileira já havia declinado para 6,8 filhos desde 1950.

Da mesma forma, as moças da faixa 2024 anos - maior concentração de noivas na segunda coorte - apresentaram a mesma descendência final das casadas na coorte anterior, em clara demonstração de que a mudança na idade ao casar não transformou o comportamento fecundo. Em outras palavras, a diminuição da descendência final deveu-se à alteração na nupcialidade e não no padrão reprodutivo. Isso porque, na primeira coorte, $97 \%$ das mulheres estavam casadas antes de completarem 30 anos (88\% já estavam casadas até os
24 anos), enquanto na segunda coorte verifica-se uma dispersão dos casamentos por todas as faixas de idade, diminuindo para $88 \%$ a proporção das uniões com noivas até 30 anos. $O$ que se tenta destacar aqui é que a modificação da nupcialidade não implicou transformação substancial nos seus comportamentos fecundos, pois a descendência final da faixa 15-24 anos permaneceu estável na coorte 2 , a da faixa de 25-29 anos cresceu na coorte 2 e, para aquelas que se casaram em faixas mais altas, verifica-se diminuição do número médio de filhos a partir de 1950. Por outro lado, ao se comparar a descendência final das mulheres da segunda coorte com as taxas brutas de fecundidade brasileira, poder-se-ia pressupor certa paridade.

Com efeito, em 1950, quando se inicia a segunda coorte, ela se situava em 6,8 filhos. Porém, em 1980, quando encerra o período de observação demográfica do presente estudo, a taxa brasileira já era de 3,8 filhos, enquanto a descendência média das emigrantes, entre 1950 e 1980, foi de 7,1 filhos. ${ }^{3}$

Aliando as idades ao casar com descendência final, a fecundidade das imigrantes de Antonio Olyntho pode ser caracterizada como não-controlada. Na tentativa de entender melhor os processos inerentes a tal perfil reprodutivo, é útil se valer do esquema desenvolvido por MATRAS (1990, p. 45).

TABELA 5

Taxa corrigida de fecundidade legítima $(0 / 00)$ das imigrantes ucranianas, por idade da mãe ao nascimento do filho, segundo idade ao casar - coorte 1

Município de Antonio Olyntho - 1895-1949

\begin{tabular}{|c|c|c|c|c|c|c|c|c|c|c|}
\hline \multirow{2}{*}{$\begin{array}{c}\text { Idade } \\
\text { ao } \\
\text { casar }\end{array}$} & \multirow{2}{*}{$\begin{array}{l}\text { № } \\
\text { cas. }\end{array}$} & \multicolumn{8}{|c|}{ Idade da mãe ao nascimento do filho } & \multirow{2}{*}{$\begin{array}{c}\text { Descendência } \\
\text { completa }\end{array}$} \\
\hline & & $\begin{array}{l}10-14 \\
\text { anos }\end{array}$ & $\begin{array}{l}15-19 \\
\text { anos }\end{array}$ & $\begin{array}{l}20-24 \\
\text { anos }\end{array}$ & $\begin{array}{l}25-29 \\
\text { anos }\end{array}$ & $\begin{array}{c}30-34 \\
\text { anos }\end{array}$ & $\begin{array}{l}35-39 \\
\text { anos }\end{array}$ & $\begin{array}{l}40-44 \\
\text { anos }\end{array}$ & $\begin{array}{l}45-49 \\
\text { anos }\end{array}$ & \\
\hline 10-14 anos & 1 & - & 600 & 400 & 200 & 800 & 400 & 200 & - & 13,0 \\
\hline $15-19$ anos & 91 & - & 530 & 534 & 419 & 354 & 339 & 133 & 25 & 10,1 \\
\hline 20-24 anos & 65 & - & - & 452 & 423 & 354 & 292 & 136 & 13 & 7,2 \\
\hline 25-29 anos & 16 & - & - & - & 279 & 353 & 311 & 122 & 25 & 4,8 \\
\hline 30-34 anos & 5 & - & - & - & - & 100 & 333 & 533 & - & 4,5 \\
\hline 35-39 anos & - & - & - & - & - & - & - & - & - & 0,0 \\
\hline 40-44 anos & - & - & - & - & - & - & - & - & - & 0,0 \\
\hline $45-49$ anos & - & - & - & - & - & - & - & - & - & 0,0 \\
\hline Total & 178 & - & 533 & 507 & 409 & 354 & 320 & 146 & 20 & 8,4 \\
\hline
\end{tabular}

Fonte: Andreazza (1999).

\footnotetext{
${ }^{3}$ Cumpre destacar que se está comparando taxas de fecundidade total, obtidas por censos, e taxas de fecundidade legítima, obtidas com reconstituição de famílias, o que, a princípio, é equivocado, pois derivam de metodologias diferenciadas. Porém, acredita-se que para fins da argumentação - destinada a mostrar que a fecundidade em Antonio Olyntho manteve-se alta enquanto declinava no Brasil - essa licença se sustente.
} 
TABELA 6

Taxa corrigida de fecundidade (0/00) das imigrantes ucranianas, por idade da mãe ao nascimento do filho, segundo idade ao casar - coorte 2

Município de Antonio Olyntho - 1950-1990

\begin{tabular}{|c|c|c|c|c|c|c|c|c|c|c|}
\hline \multirow{2}{*}{$\begin{array}{c}\text { Idade } \\
\text { ao } \\
\text { Casar }\end{array}$} & \multirow[b]{2}{*}{$\begin{array}{c}\text { № } \\
\text { Cas. }\end{array}$} & \multicolumn{8}{|c|}{ Idade da mãe ao nascimento do filho } & \multirow[b]{2}{*}{$\begin{array}{c}\text { Descendência } \\
\text { Completa }\end{array}$} \\
\hline & & $\begin{array}{l}10-14 \\
\text { anos }\end{array}$ & $\begin{array}{l}15-19 \\
\text { anos }\end{array}$ & $\begin{array}{l}20-24 \\
\text { anos }\end{array}$ & $\begin{array}{l}25-29 \\
\text { anos }\end{array}$ & $\begin{array}{c}\text { 30-34 } \\
\text { anos }\end{array}$ & $\begin{array}{l}35-39 \\
\text { anos }\end{array}$ & $\begin{array}{c}40-44 \\
\text { anos }\end{array}$ & $\begin{array}{l}45-49 \\
\text { anos }\end{array}$ & \\
\hline $10-14$ anos & - & - & - & - & - & - & - & - & - & 0,0 \\
\hline $20-24$ anos & 73 & - & - & 335 & 478 & 319 & 237 & 167 & 69 & 7,1 \\
\hline $25-29$ anos & 32 & - & - & - & 378 & 392 & 292 & 243 & - & 5,6 \\
\hline $40-44$ anos & 2 & - & - & - & - & - & - & 167 & - & 0,5 \\
\hline $45-49$ anos & 4 & - & - & - & - & - & - & - & - & 0,0 \\
\hline Total & 192 & - & 574 & 416 & 490 & 322 & 375 & 145 & 20 & 7,1 \\
\hline
\end{tabular}

Fonte: Andreazza (1999).

QUADRO 1

Regimes de fecundidade

\begin{tabular}{|llcc|}
\hline & & \multicolumn{3}{c|}{ Fecundidade } \\
\cline { 3 - 4 } & & Não controlada & Controlada \\
\hline \multirow{2}{*}{ Casamento } & Precoce & A & B \\
& Tardio & C & D \\
\hline
\end{tabular}

Tendo em vista o esquema de regimes de fecundidade, é possível situar a fecundidade das emigrantes em duas categorias. Inicialmente, pode-se apontar que as mulheres da primeira coorte apresentaram comportamentos adequados ao regime $A$, mostrando que a imigração não teve força para desestabilizar o modelo de casamento oriental. Elas mantiveram famílias numerosas e casavam-se concentradamente entre 15 e 24 anos. A partir de 1950, surgiu uma tendência à adoção do regime $\mathrm{C}$, com aumento do número de noivas entre 20 e 29 anos e distribuição de mães nas faixas de idade mais elevadas, o que não ocorreu na primeira coorte. Porém, as famílias diminuíram sua prole em um e dois filhos pelo encurtamento do tempo de constituição da família.

Para que cumprissem bem sua função procriadora, as imigrantes otimizaram o tempo de constituição da família, conjugando uma série de fatores que foram algumas vezes puramente biológicos e, na maior parte, de caráter cultural. Deve-se, inicialmente, considerar que o intervalo entre o casamento e a última concepção era amplo. Além de se casarem em idades relativamente precoces, as mulheres pariam até os 40,1 anos, na primeira coorte, e até
40,2 anos, na segunda, independentemente de suas idades ao casar. Assim, o ciclo fecundo, em ambas as coortes, era integralmente aproveitado.

Esses dados são importantes na investigação do padrão de fecundidade, dada a relação existente entre o momento em que se encerra o tempo de formação familiar (nascimento do ultimogênito) e a taxa de fecundidade geral de um determinado grupo, posto que a idade da mãe na última maternidade sempre é forte indicador de comportamento reprodutivo. Nessa linha, pode-se afirmar que, em Antonio Olyntho, a precocidade do casamento, sem dúvida, favoreceu a prole numerosa, mas a dispersão dos filhos por todo o ciclo fecundo foi fundamental para que as imigrantes produzissem as descendências indicadas nas Tabelas 5 e 6.

Para complementar a análise do regime de fecundidade, faz-se necessário verificar a maneira como as famílias dos imigrantes distribuíam seus filhos ao longo do ciclo familiar, uma vez que já se observou que elas tenderam a utilizá-lo integralmente. Determinados pesquisadores consideram que, pelo caráter acentuadamente biológico dos intervalos protogenésicos, sua duração não seria, necessariamente, indicativo da 
constituição de prole numerosa, pois a fertilidade de mulheres jovens é inferior à daquelas acima dos 20 anos, fenômeno conhecido como esterilidade das adolescentes (PRESSAT, 1967, p. 238-239).

Uma observação dos intervalos protogenésicos das imigrantes ucranianas, de fato, mostrou que os intervalos genésicos das mães mais jovens foi sempre superior aos daquelas que se casaram em faixas etárias mais elevadas.

Todavia, é pertinente observar que, nas populações em que se identificou fecundidade "natural", o intervalo protogenésico variou entre 13 e 18 meses (GUILLAUME; POUSSOU, 1970, p. 174). Considerando esse indicador, residiria nos intervalos protogenésicos outro fator que contribuiu para que a fecundidade das imigrantes ficasse entre o regime $A$ e $C$, segundo a tipologia desenvolvida por Matras: a média protogenésica da primeira coorte foi de 18,4 meses e a da segunda, 17,1 meses. O reflexo da ausência de controle de filhos é perceptível, também, no intervalo protogenésico: $39,2 \%$ dos casais da primeira coorte já tinham filho ao completar o primeiro ano de casamento e $69,1 \%$, antes de completar o segundo ano de casamento. Aqueles da segunda coorte-1950-1980 - apresentaram resultados semelhantes: $40,3 \%$ dos casais tinham seu primeiro filho até um ano de casados e $72,4 \%$ quando completavam o segundo ano de casamento.

A despeito de os intervalos protogenésicos já indicarem uma fecundidade não controlada, a descendência final entre 7 e 9 filhos das famílias ucranianas de Antonio Olyntho é fortemente tributária à distribuição assumida pelos intervalos intergenésicos. Em ambas as coortes, até 40 anos, em média, as mulheres tinham filhos em intervalos gerais de 21 a 35 meses.

Alguns estudos, ao explicarem a dimensão dos intervalos intergenésicos de populações que não praticam controle da natalidade, destacam o papel da amamentação pela sua prática prolongada. Nesse caso, a infertilidade pós-parto é explicada, por alguns autores, pelo viés biológico, relacionando aleitamento materno a um certo prolongamento da amenorréia e/ou a falhas na ovulação e, por outros, pelo viés cultural, sugerindo que determinadas culturas interditam as relações sexuais nessa fase. ${ }^{4}$

Quanto a esse aspecto, as entrevistas com as mulheres da comunidade não permitiram averiguar a presença do tabu referente ao relacionamento sexual dos casais ao longo do período de aleitamento. Porém, ao agregar a essa discussão o comportamento dos ucranianos para com os "jejuns de carne" impostos pela religião uniata, observou-se que, a despeito de seu "tradicionalismo", eles foram irreverentes ao preconizado pela Igreja. Diferentemente do que se verificou em muitas comunidades aldeãs européias, em ambas as coortes de Antonio Olyntho, as concepções em março, abril e dezembro - período em que ocorrem as "quaresmas" mais importantes dessa etnia - são semelhantes e algumas vezes maiores do que aquelas observadas nos demais meses.

Desse indicador aflora um dado importante sobre o sistema familiar desses imigrantes: a reiteração de formas ancestrais produzidas ao longo do tempo, quando o tamanho da família era decisivo para prover a defesa de seus membros e superar as dificuldades vivenciadas na milenar posição de servidão. Se assim for, justifica-se seu pequeno apego às prescrições religiosas que moldaram os comportamentos familiares aldeões desde a primeira modernidade. E, nessa mesma linha, justifica-se o fato de que, mesmo com um movimento mais recente no sentido da retração do número de filhos, as famílias dos descendentes de imigrantes ucranianos foram grandes durante todo o período estudado. Isso significa que mantiveram socialmente válido o tradicional preceito camponês de que o adequado desempenho do papel de mulher casada implica desenvolver prole numerosa.

\footnotetext{
${ }^{6}$ A esse respeito, conferir as revisões efetuadas por Yunes e Rochenzel (1977), Thomé (1985) e Burguière (1986).
} 


\section{Representações sociais que legitimaram a alta fecundidade}

Tendo em vista o que vem sendo exposto, é plausível asseverar que, na comunidade imigrante de Antonio Olyntho, os filhos sempre foram bem-vindos. Nas entrevistas com os moradores, foi possível observar tal comportamento, pois isso permitia a reprodução do sistema familiar nos moldes conhecidos e no qual a relação de reciprocidade era essencial. A esse respeito, é significativa a resposta dada por um casal estéril ao ser inquirido a respeito de quem instituiriam como herdeiro: "Quem cuidar de nós na velhice vai ficar com tudo". Se a natureza não concedeu a esse casal um herdeiro, coerentemente com sua visão, esse casal pretendia "adotar" um herdeiro para não interromper o ciclo das responsabilidades intergeracionais.

Tal crença da necessidade e da inevitabilidade dos filhos evidenciou que as mulheres da comunidade tornaram-se impermeáveis às referências "modernas" no que diz respeito às decisões reprodutivas, perpetuando, no Brasil, concepções positivas que a região de origem desenvolvera em relação à fecundidade elevada, encontrando expressão até nos objetos lúdicos. As meninas eslavas, ao brincarem com as matriozkas - bonecas com tamanhos diferentes que se encaixam, fazendo com que uma se desdobre em várias -, adentravam num universo de procriação. Diferentemente das bonecas "pedagógicas" da atualidade, que simulam um parto, as matriozkas induzem a noção de que a uma mãe cabe ter muitos filhos.

Tudo indica que os casais não planejavam sua descendência e mesmo as que tiveram poucos filhos não assumiam responsabilidade na dimensão de sua prole. Nesse caso, Anna, casada em 1948 com 31 anos - na época da entrevista já com 77 anos - sintetizou bem a ausência de controle e de planejamento familiar naquele grupo, já que ela entendia que não teve mais filhos "decerto porque Deus não quis".

Entretanto, nos relatos percebeu-se que, entre os casais mais novos, estabelecia-se o recurso a métodos contraceptivos. Ao ser indagada se não era possível controlar a quantidade de filhos, Placidina, casada na primeira coorte - que teve 11 filhos e sua cunhada, 14 - respondeu: "antes ninguém falava disso. Ninguém sabia tomar remédio como agora. [...]. Mas tinham algumas que não tinham tantos. A minha irmã teve só seis e minha cunhada só dois." Se esse depoimento indica o conhecimento tardio da pílula anticoncepcional, outros evidenciam que tal conhecimento veio do "centro para a periferia". Alega-se que as mulheres que migraram para Curitiba conheceram antes a possibilidade da interferência nas concepções. Anastácia, que se casou em 1957 e teve dez filhos, nascidos entre 1957 e 1973, enfatizou esse aspecto: "antes de casar ninguém falou que podia ter menos filhos. Depois que eu casei sim porque viram que eu fui tendo bastante. A minha cunhada dizia para eu tomar comprimido. Ela trabalhou em Curitiba e aprendeu lá o comprimido."

Essa explicação encontra respaldo na precariedade do atendimento médicohospitalar local, pois, no período coberto por esse estudo, os hospitais mais próximos ficavam em cidades vizinhas, como São Mateus do Sul e Lapa, em distâncias aproximadas de 40 quilômetros. Dados do IBGE, relativos a 2000 , mostram que até essa data o município ainda não contava com nenhum leito hospitalar, apenas com sete postos de saúde.

De qualquer maneira, a investigação da contracepção esbarra com resistências pessoais, culturais e religiosas, em que dificilmente se pode penetrar. Alguns fragmentos nas falas das mulheres permitiram entrever, contudo, que elas conheciam formas de controle da natalidade, ainda que não praticassem. Uma entrevistada, que casou em 1957 e teve nove filhos, esclarece: "tinha como evitar os filhos. Tudo vinha da farmácia porque nós não sabíamos fazer nada. Tinha umas lá que faziam xaropadas, chás, mas sei lá se isso dava certo." Com nove filhos, essa mãe efetivamente pode não ter provado as xaropadas e os chás abortivos que algumas mulheres possivelmente tomaram.

No entanto, as médias gerais de fecundidade - entre 1895 e 1980 - são reflexo 
de uma genérica despreocupação social quanto ao controle dos nascimentos. Como já foi mencionado, comparando as duas coortes, ao se isolarem os grupos de muIheres casadas entre 15 e 29 anos, verificase, inclusive, um leve aumento do número médio de filhos na segunda coorte - entre as mulheres da faixa de 25-29 anos. Disso pode-se depreender que o padrão de fecundidade apresentado pelas ucranianas tem uma relação bastante estreita com o apego a um sistema familiar ancestral, cuja permanência foi possibilitada pelas condições em que se instalaram no Brasil: isolados em área rural e pouco atingidos pelos inúmeros agentes modernizadores que favoreceram a transformação dos sistemas familiares brasileiros ao longo do século $X X$. Nessas condições, os imigrantes e seus descendentes precisaram efetuar pequenos ajustes nas práticas familiares que exerciam na Galícia e, assim, desdobraram costumes produzidos em resposta a necessidades sociais diferenciadas das que a realidade colonial Ihes colocava.

O princípio interpretativo de que os sistemas familiares correspondem às opções coletivas decorrentes de uma determinada experiência temporal adquire maior relevo quando se compara a dinâmica da fecundidade dessas imigrantes com a das ucranianas que se dirigiram ao Canadá. A emigração para o Canadá processou-se paralelamente à do Brasil, sendo que em muitas aldeias os fluxos de emigrantes repartiram-se entre os dois países. Com isso, pode-se pressupor que tenham emigrado para destinos diferentes, porém levando as mesmas concepções a respeito da formação familiar.

Um estudo de Wolowina (1980, p. 161188), com base em censos decenais, mostra, efetivamente, que as mulheres ucranianas canadenses tinham uma fecundidade maior do que as canadenses de qualquer outra origem étnica, nos anos de 1931, 1941 e 1951. A partir de então, houve brusca diminuição nas taxas de fecundidade das mães ucranianas canadenses, ficando a descendência final por volta de dois filhos na década de 70 .

Os contingentes de ucranianos fixados no Canadá vivenciaram condições diferenciadas dos que vieram ao Brasil, e em particular dos que se radicaram em Antonio Olyntho, pois lhes foi possível rápida mobilidade social ascendente numa sociedade que se modernizava a passos largos e oferecia condições de escolaridade e variedade de empregos, tanto aos homens quanto às mulheres. Nesses fatores residiria uma justificativa para tamanha diferença entre as taxas de fecundidade das mulheres ucranianas canadenses e as obtidas no presente estudo. Essa comparação serve para dimensionar a interferência do contexto em que está inserida uma determinada população em suas decisões reprodutivas, bem como para reafirmar o pequeno valor da dimensão biológica na procriação - "legítima" ou não - , pois as taxas de fecundidade expressam consensos coletivos em torno de certos comportamentos muito associados à ordem cultural. Entre tais consensos, destacam-se as idéias socialmente ativas a respeito do papel feminino no conjunto das relações sociais, como também as concepções relativas aos filhos e as relações intergeracionais.

Nessa linha, se voltarmos os olhos para a Ucrânia, matriz cultural das duas dinâmicas demográficas tão diferenciadas comparadas anteriormente, encontraremos uma população que, no século XX, apresentou uma trajetória em descompasso com tendência genérica da alta fecundidade até fins do XIX.

Um estudo de Meslé, Pison e Vallin (2005) indica que, até meados dos anos 20, a Ucrânia apresentava uma pirâmide populacional com formato triangular, própria das populações com altas fecundidade e mortalidade. Tal formato expressa uma população jovem e com grande potencial de crescimento. Pressupõe inclusive um prognóstico de explosão demográfica naquele país se, mantida a alta fecundidade, agissem os fatores que aumentaram a expectativa de vida no século XX e diminuísse a constante emigração. Diferente do esperado, o acaso interferiu com dois acidentes demográficos que desviaram essa provável rota demográfica: a grande fome de 1933 e a Segunda Guerra Mundial. O efeito desses "reguladores de população" foi a diminuição da população ucraniana de 42,6 para 32,1 milhões de habitantes entre fins da década 
de 20 e 1945. Fixando-se apenas nos dados da fecundidade, os autores mostram que ela manteve constante declínio mesmo após a Segunda Guerra (de 2,5 filhos, em 1950, estabilizou-se em torno de 2 filhos por mulher, entre as décadas de 60 e 80), chegando aos anos $90 \mathrm{com}$ uma das mais baixas taxas da Europa ( 1,1 filho por mulher) e com taxa de crescimento negativa $(-0,14 \%)$ (MESLÉ; PISON; VALLIN, 2005, p. 2).

De outro ponto de vista, Goody aponta uma motivação diferente a ser considerada nessa trajetória da população ucraniana: sua inserção no bloco dos países socialistas. De forma abreviada, e em muito decorrente das posições de Engels em relação à incompatibilidade do sistema familiar "burguês" num quadro de coletivização social, pode-se reter que a política familiar socialista permitia o aborto e o divórcio e coibiu as coerções religiosas quanto à contracepção. Além disso, abriram-se muitas oportunidades de emprego às mulheres e anulou-se o sistema de heranças, afetando radicalmente os sistemas familiares daqueles países (GOODY, 2001, p. 156).

Em suma, novamente observam-se as contingências temporais agindo e retirando da população da Ucrânia a possibilidade de manter a constância das taxas de fecundidade apresentadas até as primeiras décadas do século XX. A precipitação de uma série de fenômenos exógenos às práticas familiares impeliu os casais e as mulheres a repensarem os parâmetros que orientavam as decisões reprodutivas, cujo resultado foi uma radical transformação na dinâmica demográfica daquela sociedade.

\section{Por que a fecundidade das ucranianas radicadas em Antonio Olyntho se manteve inalterada?}

Para que houvesse a prática do controle da natalidade das mulheres ucranianas de Antonio Olyntho, seriam necessárias mudanças estruturais nesse grupo social. A diminuição voluntária da prole não decorre simplesmente da adoção de práticas anticoncepcionais; implica, sobretudo, romper com um determinado sistema familiar. Oras, o grupo doméstico mais característico em
Antonio Olyntho foi aquele com domicílios relativamente complexos, delineando com mais freqüência famílias-tronco ligadas à atividade agrícola, basicamente para o autoconsumo. Isso é indicativo da manutenção de uma estrutura domiciliar complexa, própria das regiões rurais tradicionais.

Os recém-casados moravam durante os primeiros tempos na residência dos pais de um dos noivos; normalmente, na casa dos pais do noivo. Se o casal não era formado por herdeiros, essa moradia era temporária; caso contrário, definitiva. O modelo domiciliar baseava-se, mais freqüentemente, na residência patrilocal, com a mulher assumindo a família do marido como sua. Nas entrevistas, as mulheres de diferentes gerações sempre indicaram pertencimento ao grupo domiciliar do marido, de maneira que transcendia à simples adoção patronímica.

É possível pensar que as unidades residenciais com forma de família-tronco foram decorrência da imigração. Burguière (1986, p. 37-39) apontou a freqüência de unidades residenciais com estrutura complexa no Leste europeu. Para o autor, nas regiões em que a relação senhorial assumiu formas extremas, era grande a porcentagem dessa organização doméstica que teria, inclusive, raízes remotas. Nessas bases, entre os camponeses russos e poloneses, era comum a coabitação de dois ou mais casais, por ser particularmente conveniente à economia regional de grandes domínios onde a relação de trabalho não se baseava em salários.

Ao associarem estrutura domiciliar com racionalidade econômica, os estudos referem-se, muito comumente, às análises de Chayanov (1966). Com base em estatísticas agrárias, o autor demonstrou a interdependência entre alterações na dimensão domiciliar - ocorridas ao longo do ciclo familiar - e a disponibilidade de oferta de mão-de-obra. Nessa esteira de interpretação, Kula (1972) colabora demonstrando que, nas propriedades senhoriais da Polônia do século XVIII, as famílias extensas eram incentivadas tanto pelos nobres - preocupados com fartura de mão-de-obra - quanto por uma relação de compromisso moral das comunidades camponesas para com seus membros. $\mathrm{O}$ autor 
detalha, assim, as inúmeras estratégias que os nobres desenvolveram para manter como seus servos os filhos casados e as filhas adultas, explorando o mesmo domínio que seus pais. Indica, ainda, enquanto elemento facilitador de composições complexas, regulamentações oficiais que favoreciam os domicílios dos camponeses a tomarem sob sua guarda órfãos e parentes próximos ou distantes (KULA,1972, p. 957-958).

$O$ desenvolvimento de unidades residenciais com estrutura ampliada entre o campesinato europeu oriental devia-se, sobretudo, ao fato de a propriedade não ser individualizada. Não era o indivíduo isolado que possuía com exclusividade os recursos produtivos, mas sim a família. Com base nisso, Macfarlane (1980, p. 33-38) reitera que, nos casos em que a propriedade é do grupo e não do indivíduo - e onde o trabalho familiar é importante na produção -, com freqüência as famílias são mais numerosas, uma vez que os filhos, co-proprietários com os pais, permanecem em casa por mais tempo do que nas sociedades em que são lançados desde cedo no mercado de trabalho. Segundo o autor, parece claro que, no século XIX, a unidade residencial da Europa Oriental era amiúde composta de mais do que a família nuclear. Por isso mesmo, "a família camponesa tradicional constitui-se em geral em três gerações".

Considerando que os domicílios complexos têm raízes profundas na experiência de diferentes sociedades agrárias e foram particularmente disseminados entre o campesinato da Europa Oriental, depreende-se que a formação de grupos domésticos complexos entre os imigrantes que se dirigiram a Antonio Olyntho traduz a perpetuação de uma morfologia doméstica na qual já transitavam. No entanto, deve-se apontar que, se a característica das residências camponesas do Leste europeu tendia para o tipo extenso, as que se formaram em Antonio Olyntho, como já dito, eram grupos domésticos semelhantes à famíliatronco. A partir disso, é melhor afirmar que os imigrantes trouxeram uma tradição na formação de unidades domésticas extensas, mas que a imigração transformou o princípio que regulava tal complexidade.
Eles foram inseridos numa política de instalação em pequenas propriedades e sobretudo iniciados na efetiva prática da propriedade privada. Aqui assume real sentido a frase escrita por um pároco local, indicando que abandonaram a Galícia para satisfazer "o desejo de serem senhores de si mesmos". Naturalmente, a posse individualizada definiu alterações na composição doméstica, sobretudo porque, em Antonio Olyntho, os lotes medindo, geralmente, dez alqueires eram suficientes apenas para prover o trabalho e sustento a um grupo doméstico com proporções reduzidas. A manutenção de uma família patriarcal, in totum, tornou-se inadequada à nova realidade fundiária dos imigrantes. É lícito pensar que, da necessidade de rearranjo na composição domiciliar, resultou uma diminuição do número de moradores sob o mesmo teto, imprimindo traço mais acentuado no perfil de família-tronco. A redução do número de coabitantes não extinguiu, contudo, como será visto adiante, a permanência do código de reciprocidade tradicional que detém estreita relação com a forma pela qual uma sociedade organiza o sistema de transmissão da herança.

Sabe-se das diferentes tradições camponesas quanto à sucessão, oscilando entre a indivisibilidade da terra até a paridade de direitos entre os herdeiros (SHORTER, 1977, p. 35; BERKNER, 1976, p. 71). Em algumas regiões da Áustria, por exemplo, a terra era prometida a somente um dos filhos, geralmente o mais velho; em outras, quem herdava era o mais novo, de maneira a permitir que o pai se mantivesse por mais tempo na direção dos negócios familiares. Nesses casos, os demais filhos, não herdeiros, recebiam compensação financeira ou o direito de se manterem morando com a família, sob a condição de não se casarem. A despeito das variações locais, um aspecto fica muito claro: a prática de diferentes regras para a sucessão patrimonial esteve sempre relacionada com a estrutura familiar vigente.

Entre os imigrantes em estudo, a transmissão do patrimônio mais freqüente foi aquela na qual o filho mais novo articulava sua permanência no grupo domiciliar paterno à sucessão de domínio da propriedade. Essa 
estratégia estaria refletindo uma adaptação dos costumes que os imigrantes trouxeram consigo. Embora entre os camponeses da Europa Oriental do século XIX e início do XX houvesse a concepção de a propriedade ser algo pertencente à família no tempo, isso não significava nem direito comunal $e$ muito menos que um conjunto de pessoas possuísse frações ideais desse bem.

A prática de os filhos não terem, isoladamente, direito à posse foi exemplificada por Shanin, quando apresentou as decisões tomadas pelas Cortes de Apelação da Rússia, em final dos anos oitocentos. Por elas, as terras eram consideradas propriedade não da pessoa legalmente registrada como sua proprietária, mas sim de todos os membros da família, sendo o seu chefe apenas o representante da mesma. Com base nesse entendimento social da propriedade, Macfarlane (1980, p. 34) identifica que entre "as raízes da destruição do sistema campesino [estaria] a evolução do conceito de que o indivíduo tem direito à propriedade face a outros indivíduos". Pela inexistência da noção de herança da forma desenvolvida em sociedades não camponesas, outra característica peculiar é que o "legado de uma geração a outra não envolvia necessariamente a morte de um dos pais e era encarada legalmente como a partilha da propriedade da família entre seus membros".

Alguns estudos sobre imigrantes no Brasil apontam estratégias para manter a indivisibilidade dos lotes (WOORTMANN, 1995), o que reforça a noção de que, muitas vezes, códigos culturais específicos encontram maneiras de burlar a lei da sociedade envolvente. Sabe-se que o Código Civil Brasileiro, em vigor desde 1916, prevê paridade de direitos entre os herdeiros. $E$, foi justamente nas formas da Lei que, entre os imigrantes de Antonio Olyntho, buscou-se preservar, o mais possível, a integridade dos lotes. Lendo a escritura de partilha amigável do espólio de Leonardo, em 1934, tem-se conhecimento de que ele deixou para a viúva e seus dois filhos "um lote de terras de dez alqueires adquirido por compra feita ao governo do Estado, no valor de dois contos de réis". Pelo Código Civil Brasileiro, caberia à viúva Anastácia a quantia de mil contos de réis e, aos filhos, em partes iguais, quinhentos contos de réis. No entanto, como se lê nos apontamentos do cartório distrital de Antonio Olyntho,

em virtude de se achar a viúva meeira de há muito tempo residindo em companhia de seu filho Estefano, que é quem lhe está sustentando e cuidando por quasi não poder mais trabalhar, foi então por ela dito, que renuncia, como de fato renunciado tem, à sua meação, em favor do dito Estefano, para que este seja adjudicado na sua referida parte, ficando assim subrogado em todos os direitos que lhe assistem com relação a esta partilha e seus ônus.

Em outros casos, verifica-se a partilha paritária, sendo que, findo o processo legal, os herdeiros, principalmente quando já tinham migrado, doavam suas parcelas de herança aos irmãos que permaneceram na localidade, basicamente àqueles que cuidavam dos pais. Neste caso estão Felipe e sua esposa Tecla, Simão e sua esposa Ahafia, residentes em Três Barras, "que cederam e transferiram aos outorgados aceitantes Pedro e Demétrio, todos os seus direitos hereditários que Ihes cabia no espólio de seus pais e sogros João e Maria".

Com base nesse recurso, ainda na atualidade, é consenso entre as famílias mais tradicionais que, ao filho mais novo, caibam a manutenção da terra e o dever de cuidar da velhice dos pais; em outras palavras, o mais novo é responsabilizado concomitantemente pela perpetuação do patrimônio e pela reprodução da lógica familiar.

Disso decorre retomar um ponto do que ficou aberto quando se discutiu a alteração da idade ao casar da segunda coorte, formulando a seguinte indagação: até que ponto a mudança na nupcialidade, a partir de 1950, não corresponde a um efeito dos rearranjos que a imigração impôs ao sistema familiar? Se o herdeiro preferencial passou a ser o ultimogênito, cabia a ele esperar a migração dos irmãos mais velhos (ou um eventual casamento deles com herdeira local) antes de contratar seu próprio casamento.

Evidentemente, grande parte dos terrenos originais foi objeto de divisão, e alguns moradores mais idosos afirmam que, no início da colônia, houve uma forte inclinação para se fazer partilhas igualitárias. Essa 
tendência poderia explicar a quantidade de minifúndios que apareceram em cadastramentos, como o do Incra, em 1964, e a pauperização atual dos proprietários de microlotes. Sabe-se que mesmo dez alqueires são parcamente suficientes para a subsistência de um grupo doméstico de porte mediano; no entanto, os colonos sustentavam uma prole em média de sete a oito filhos em todo o período observado.

Pode-se pensar, assim, que tal tendência inicial a heranças paritárias tenha favorecido a instituição do ultimogênito enquanto o herdeiro ideal. Aquelas famílias que puderam manter o lote inicial indiviso retomaram a coabitação, no sentido de evitar a pobreza geral que viam entre os domicílios fragmentados e garantir o exercício da relação de reciprocidade tradicional. Nesses termos, pode-se colocar a hipótese de que a experiência dos imigrantes como pequenos proprietários forjou o ultimogênito como sucessor. Lotes pequenos não proviam as necessidades de uma família extensa, nos moldes patriarcais. Foi imperioso restringir o grupo de coabitação.

Aos filhos mais velhos restou buscar oportunidades mais freqüentemente fora da localidade. O Paraná ofereceu, ao longo do século $X X$, oportunidades em várias "frentes pioneiras" e não é por acaso que o Norte Novo tenha tantos contingentes de ucranianos. Abandonando a casa paterna, os "filhos e filhas excedentes" levavam uma força de trabalho desnecessária em um lote de dez alqueires, além de garantir a diminuição do consumo doméstico. Assim, no momento em que a capacidade produtiva dos pais começava a declinar, o ultimogênito, em condições de pleno trabalho, trazia para o lar uma esposa trabalhadora.

Entender o conjunto de fatores presentes nesse sistema familiar, particularmente a estrutura domiciliar e os costumes relativos à sucessão, foi fundamental para compreender a manutenção de altas taxas de fecundidade

\section{Referências bibliográficas}

ANDREAZZA, M. L. Paraíso das delícias: estudo de uma comunidade imigrante ucraniana. 1895-1995. Curitiba: Aos Quatro Ventos, 1999. na comunidade. Fatores como idade precoce no casamento, intervalos genésicos curtos e seqüenciados, ocupação de todo o período fértil da mulher podem compor altas taxas de fecundidade. Mas, do ponto de vista da história da família, esses comportamentos traduzem uma determinada prática familiar conformando índices de um comportamento socialmente aceito e que, por isso mesmo, detém garantia de permanência.

Assim, pode-se finalizar essa análise apontando que a fecundidade dos imigrantes manteve-se alta até o final do período estudado justamente porque, para os descendentes de ucranianos em Antonio Olyntho, a representação de família que abriga a noção de prole extensa não encontrou o seu limite. Porém, as condições coloniais exigiram plasticidade na atualização do sistema familiar ancestral, o que determinou uma opção por excluir os filhos excedentes do convívio doméstico, já que a alta fecundidade criou sucessivas gerações de migrantes. Foi o preço pago para que certo número de famílias mantivesse seus compromissos com a tradição. No interior dessa racionalidade particular, permaneceram ativos os princípios da autoridade patriarcal, uma rígida definição dos papéis familiares e a crença de que o correto encadeamento das coisas implica a responsabilidade das gerações mais novas para com as que as antecederam. Aos que deixaram Antonio Olyntho, abriram-se oportunidades de conhecer outros sistemas familiares.

Mesmo que tenha sido observado apenas um segmento das famílias do atual município de Antonio Olyntho, pode-se cogitar que um possível efeito da atitude radical dos que aí se mantiveram seja o fato de o município incluir-se entre os espaços de severa pobreza paranaense. Aí, mais de $40 \%$ de domicílios são de pobres, assim definidos pela renda familiar per capita situar-se em $1 / 2$ salário mínimo (IPARDES, 2003, p. 11). Porém, esse dado enseja outro tipo de discussão.

ANDERSON, P. Linhagens do estado absolutista. São Paulo: Editora Brasiliense, 1985. 
YUNES, J.; ROCHENZEL, V. S. Inter-relação entre lactação, fecundidade e variáveis socioeconômicas em mulheres no distrito de São Paulo. In: BERQUÓ, E.; OLIVEIRA, M.C.; CAMARGO, C.P. (Orgs.). A fecundidade em São Paulo: características demográficas, biológicas e socioeconômicas. São Paulo: Ceprap - Editora Brasileira de Ciências, 1977.

BERKNER, L.K. Inheritance, land tenure and peasant family structure: a German regional comparison. In: GOODY, J.; THIRSK, J.; THOMPSON, E. Family and inheritance. Cambridge: CUP, 1976.

BIDEAU, A. Mecanismos auto-reguladores de populações tradicionais. In: MARCíLIO, M.L. (Org.). População e sociedade. São Paulo: Vozes, 1984.

BURGUIÈRE, A. et al. Histoire de la famille: le choc des modernités. Paris: Armand Colin, 1986.

CARVALHO, J. A. M. de. Para onde iremos: algumas tendências populacionais no século XXI. Revista Brasileira de Estudos de População, v. 18, n.1/2, jan./dez. 2001, p. 7-13

CHAYANOV, A.V. The theory of peasant economy. Illinois: Richard D. Irwin, Inc., 1966.

DUPÂQUIER, J. Pour la démographie historique. Paris: Presses Universitaires de France, 1984.

FLANDRIN, J. L. Famílias: parentesco, casa e sexualidade. Lisboa: Editorial Estampa, 1992.

FLEURY, M.; HENRY, L. Nouveau manuel de dépoullement et exploitation de l'état civil ancién. Paris: Ined, 1979.

GUILLAUME, P.; POUSSOU, J.P. Démographie historique. Paris: Armand Colin, 1970.

GOODY, J. La familia europea. Barcelona: Critica, 2001.

HAJNAL, J. European patterns in perspective. In: GLASS, D. V.; EVERSLEY, D.E.C. Population in history: essays in historical demography. Londres: E. Arnold, 1965.
HENRY, L. Demografia. Barcelona: Editorial Labor, 1976.

HIMKA, J. P. Galician villagers and the ukrainian national movement in the nineteenth century. Edmonton: Canadian Institute of Ukrainian Studies, 1988.

HOBSBAWM, E. A era dos impérios: 18751914. Rio de Janeiro: Paz e Terra, 1988.

IPARDES. Famílias pobres no Estado do Paraná. Curitiba: Ipardes, 2003.

KULA, W. La seigneure et la famille paysanne dans la Pologne du XVIIle. Annales... Paris, 1972.

MACFARLANE, A. Família, propriedade e transição social: as origens do individualismo inglês. Rio de Janeiro: Zahar Editores, 1980.

História do amor e do casamento. São Paulo: Companhia das Letras, 1990.

MARTINE, G. (Org.). População, meio ambiente e desenvolvimento: verdades e contradições. Campinas: Ed. da Unicamp, 1993.

MARTINE, G. A redistribuição espacial da população brasileira durante a década de 80. Rio de Janeiro: Ipea, 1994 (Texto para discussão no 329).

MESLÉ, F.; PISON, G.; VALLIN, J. FranceUkraine: demographic twins separated by history. Population \& Societies, n. 413, June 2005 - The monthly newsletter of the Institut National d'Études Démographiques, ISSN 018477 83. Disponível em: <http:// www.ined.fr>.

MORAZÉ, C. Os burgueses à conquista do mundo: 1780-1895. Lisboa: Edições Cosmos, 1965.

OLIVEIRA, J. de C. O.; ALBUQUERQUE, F. R. P. de C.; LINS, I. B. Projeção da população do Brasil por sexo e idade para o período 1980-2050 - Revisão 2004. Estimativas anuais e mensais da população do Brasil e das unidades da federação: 1980-2020. Estimativas das populações municipais. Metodologia. Rio de Janeiro, IBGE, 2004. Disponível em: <http://www.ibge.gov.br/>. 
PRESSAT, P. EI análisis demográfico. México: Fondo de Cultura Económica, 1967.

ROWLAND, R. População, família, sociedade. Portugal, séc. XIX-XX. Oeiras: Celta Editora, 1997.

SHORTER, E. Naissance de la famille moderne: XVIII e XX siècle. Paris: Éditions du Seuil, 1977.

THOME, A. M. T. Análise dos determinantes próximos da fecundidade. In: ENCONTRO NACIONAL DE ESTUDOS POPULACIONAIS,
IV. Anais... Belo Horizonte: Abep, 1985, p. 903-944.

WOLOWYNA, J. E. Trends in marital status and fertility of ukrainians in Canadá. In: PETRYSHYN, W.R. (Edit.). Changing realities: social trends among ukrainian canadians. Alberta: Canadian Institute of Ukrainians Studies, 1980, p.161-188.

WOORTMANN, E. F. Herdeiros, compadres e vizinhos: colonos do Sul e sitiantes do Nordeste. São Paulo-Brasília: Hucitec/ Edunb, 1995.

\title{
Resumen
}

Sobre regímenes demográficos restringidos: Comportamiento reproductivo y cultura familiar entre los ucranianos en el medio rural paranaense (1895-1980)

El estudio hace un seguimiento de la dinámica familiar de inmigrantes originarios del área de la actual Ucrania, llegados a Brasil en 1895 y establecidos en el área rural de Paraná, en la colonia Antonio Olyntho. Dada la alta fecundidad legítima del grupo, en las cohortes establecidas para el estudio (1895-1949/1950-1980), se procuró comprender las razones del mantenimiento de una descendencia final alta a lo largo de todo el período analizado (entre 8 y 9 hijos, en la primera cohorte, y entre 7 y 8 en la segunda) y lo que eso implicó en términos de organización social, familiar y doméstica. De esto restó considerar que el comportamiento reproductivo es fruto de un complejo sistema de representaciones, en el cual interactúan modos de concebir las relaciones de género y las inter-generacionales, así como el papel del casamiento y de la constitución familiar. Si así fuera, las prácticas concernientes a la fecundidad corresponden, sobremanera, al ejercicio social de una determinada visión del mundo. En especial en los grupos que viven en cierto aislamiento social, las posibilidades de reproducir modelos ancestrales de reposición generacional son favorecidas. Entre los inmigrantes estudiados, casi un siglo en Brasil fue insuficiente para cambiar el sistema familiar que vino en su bagaje: aquí continuaron reproduciendo una prole extensa, aunque por eso hubieran activado una continuada migración de los hijos excedentes.

Palabras-clave: Fecundidad. Inmigrantes. Sistema familiar. Ucranianos.

\begin{abstract}
On restricted demographic regimes: reproductive behavior and Ukrainian family culture in rural areas of the Brazilian State of Paraná (1895-1980)
\end{abstract}

This study focuses on the family dynamics of immigrants from the present country of The Ukraine. The ancestors of these families came to Brazil in 1895 and settled in a rural area of the State of Paraná known as Colônia Antonio Olynto. Due to the group's high legitimate fertility rate in the cohorts established for the study (1895-1949/1950-1980), the research focused on understanding the maintenance of this high rate during the period analyzed (between 8 and 9 children in the first group and 7 and 8 in the second) and the consequences in terms of family, home and social organization. In other words, the analysis questions the reasons why this group tried to perpetuate a reproductive system that historically corresponded to the realities of a quite different social space, when, in their adopted country the gross fertility rate was 
quickly reduced, particularly in the period that corresponded to the second group of the study. The only conclusion possible would seem to be that reproductive behavior is the result of a complex system of representation interfacing the different ways of conceiving gender-based and inter-generational relations. Also important are the role of marriage and the establishment of a home. If this is so, fertility behavior overwhelmingly corresponds to the social exercise of a specific perception of the world, especially in groups that live in social isolation, where the opportunity to reproduce ancestral models of generational replacement is favored. Among the immigrants studied, almost a century in Brazil was not enough to change the system that the families brought with them from The Ukraine. In Brazil they repeated behavior of having large numbers of offspring, even at the cost of the inevitable migration of many of their children in adulthood.

Keywords: Fertility. Immigrants. Family system. Ukrainians.

Recebido para publicação em 10/08/2007. Aceito para publicação em 25/04/2008. 